\title{
HABLEMOS DE OBSCENIDADES: A PROPÓSITO DEL LIBRO GEOGRAFÍA DE LA CANASTA FAMILIAR ALIMENTARIA EN CALDAS
}

\section{Elmer Castaño Ramírez}

"Este es un mundo loco,

José Saramago

\section{Manizales, 2009-08-16 (Rev. 2009-11-06)}

Si la Geografía se entiende como la ciencia que se encarga de la comprensión de las relaciones sociedad naturaleza con un fundamento espacial y mediante la aplicación de las teorías de localización y distribución de los hechos, entonces la Geografía, como nominación, aplica a este libro por ser un cuerpo teórico creado por el hombre y para el hombre con el propósito de satisfacer las necesidades de ubicación de la relación dinámica de los grupos humanos que habitan el territorio caldense, mediante la integración de espacios social y económico construidos en común unión con la naturaleza, y siempre entendida dicha relación como en polución

Es situar y estar al tanto que el espacio del saber culinario, del saber nutricional, son espacios antropológicos compartidos vinculados con los espacios de las mercancías agrarias producidas o importadas al territorio, que por medio de intercambios llena de significaciones las plazas de mercado y el centro del barrio, la tienda, los puntos nodales de encuentro. El espacio geográfico aquí incluye la proximidad, las expresiones afectivas, las relaciones sociales, la historia en común, los elementos estéticos y de significación general compartidos alrededor de una mesa.

Cualquier angustia gubernamental se tranquiliza cuando, desde la "estadística" como ciencia del Estado, con un constructo como la "canasta familiar", uniforman y validan los consumos a partir de ciudades capitales y asumen que los municipios tienen las mismas ingestas de los centros poblados grandes. En la democracia centralizada, las preocupaciones alimentarias no llegan más allá de los promedios nacionales, cualquier rebaja en precios se muestra como un logro e inclusive se transforman estadísticamente las cifras para mostrar resultados mejores y se asumen como hechos. Se desconoce que los datos no son sucesos ni objetos, son simples registros, descripciones o recuerdos de eventos, que se transforman en representaciones relacionales para entregar sólo esbozos teóricos, se convierten en simples artificios y a pocos les interesa la evidencia de ese sector agrario lejano o los municipios de fisiografías arrugadas -como la de los andes centrales- donde hay personas que se alimentan. Es que más allá del mapa, hay hombres y mujeres, niños, ancianos que viven la realidad de los modelos explicativos de las canastas (nombre cercano al continente de los alimentos) para las familias (como agrupaciones humanas nucleadas) en los contenidos promediados (artículos para suplir las necesidades alimentarias) y que sirven de espejo para reflejar la estructura pasada del hambre. Siempre es mejor silenciar mediante estadísticas la cotidianidad de los individuos como lo solemos hacer en ciencias, dejar hablar sólo la teoría y restarle importancia al dolor, ocultándolo.

Como lo escribimos en el documento, las necesidades vitales como la alimentación se traducen en sensaciones de carencia (hambre) que se unen al deseo de hacerla desaparecer. Es aquí donde se dan los principios económicos de unión de un hombre y los elementos que le sirven como alimento. Como son necesidades sin las cuales la subsistencia no es posible o se torna limitada la vida misma y tiene, además, la urgencia diaria e impostergable (no se puede esperar a que surjan políticas alimentarias para solucionar el hambre diaria), están completamente ligadas al ser humano biológico y a su corporeidad (la biología es tiempo, capacidad productiva, capacidad reproductiva, capacidad afectiva, en fin, capacidad de vivir plena e integralmente y ello sólo se logra a partir de una adecuada nutrición) y las necesidades son completamente individuales (no de promedios); se requiere un conocimiento de las condiciones locales para incidir sobre los mecanismos de mejora y un trazado de estrategias con mayor conocimiento de causa, allí se inicia nuestra intención de no abundar en análisis de conjunto más allá de lo que la investigación permite y dejar este manuscrito en una fase sustancialmente descriptiva y delimitante del problema alimentario en Caldas por municipio y subregión.

Pero, con el estudio de la caja negra "canasta familiar alimentaria" que vincula acercamientos a la realidad nutricional con las preocupaciones estatales, no podemos soslayar el hambre como objeto de estudio y que Turró definió como un acto consciente de la necesidad de restablecer los elementos 
perdidos en el medio interno del organismo. A partir de estas consideraciones, Turró (1912) estableció que cuando el organismo entra en contacto por primera vez con el alimento éste se relaciona con la conducta y establece un control sobre ella. Asume que es necesaria la experiencia repetida de esta conducta con el alimento para que el organismo aprenda a discriminar sus características nutricias. De este aprendizaje nace el apetito como otro elemento psicológico de la alimentación. Turró añadió que el apetito no nace sino que se hace por medio de experiencias vivas y que contra lo que se pudiera pensar, el apetito no es un hambre distinta a la celular, es una hambre representativa de las cosas alimenticias. La característica principal del trabajo de Turró fue asumir que el hambre y específicamente en conjunto con el apetito, son determinantes para que un organismo se alimente. La unión del componente orgánico (el reflejo trófico) y el factor psicológico (el hambre) es el medio para conocer el contexto alimentario, por su parte, el apetito entendido como conocimiento aprendido, es el que determina nuestra experiencia en la selección y preferencias alimentarias. Bajo este enfoque, alimentarse se convierte en un conocimiento adquirido por aprendizaje y no basado en un instinto y por ello es regional (espacial, geográfico). Así, el hambre podría ser conceptuada como la emisión de conductas dirigidas a lograr el consumo de alimento en los organismos, aquí interviene el deseo vital por el objeto (alimento) que entrará a ser parte integral del ser y que unido al tiempo (no da espera), le otorgan el carácter de aprovechabilidad que tiene el hambre.

Pero con Messer (1995), el hambre es un fenómeno que debe ser abordado a partir del estudio de las relaciones entre los individuos y el alimento. Estas relaciones tienen un marco de estudio muy amplio, donde las relaciones pueden abarcar: las vías de selección de alimento, los ritos y tradiciones generados en torno a un determinado tipo o grupo de alimento, así como la denominada cultura alimentaria y el temor por no conseguir la ingesta diaria. Para disminuir tal preocupación, establecimos otros conceptos que minimizan el temor a padecer hambre tales como la seguridad alimentaria y nutricional y, ligada a ello, otras miradas políticas con conceptos como soberanía alimentaria y solvencia alimentaria.

Cada una de las relaciones anteriores está caracterizada por diferentes conductas hacia los alimentos. Con la diversidad de actitudes podríamos observar formas rituales o contrastes marcados como periodos de privación alimentaria que son particulares a diversos grupos étnicos. Pero si bien el acto de comer origina situaciones extremas entre el ayuno y las comilonas, las conductas opuestas de consumos permanentes y bien surtidos, mantienen una particular confianza en que el alimento siempre estará seguro para todos, con lo que se teoriza alrededor del hambre que no se vive y se menosprecia el papel social del alimento en los múltiples grupos que habitamos a Caldas. Específicamente, en los seres humanos, la influencia de la familia ha sido analizada bajo diferentes criterios tales como: los factores culturales, elaboración y conservación de alimentos, transporte y consumo de los mismos, prohibiciones y tabúes nutricionales, e incluso, la influencia de los ritos mágicos y religiosos que envuelven al fenómeno alimentario. Así, la alimentación es estudiada como un fenómeno dependiente de la influencia de múltiples factores. Por su parte, la perspectiva psicológica aporta elementos que identifican un estado de hambre en relación con factores: a) ambientales; b) de aprendizaje; c) conductuales; y, d) motivacionales. Estos elementos plantean necesariamente que un organismo interactúe con el ambiente y posiblemente dirijan la conducta de selección y preferencia de alimentos. Una cosa queda clara, no se pueden identificar grados de hambre, así políticamente se predetermine que hay unos condenados a padecerla y otros sólo dispuestos a estudiarla, analizarla y decidir en consecuencia.

Son múltiples los vínculos que se pueden hacer en este tema tan complejo, del cual dejamos sólo enunciados con este libro, los espacios antropológicos del hambre como planos de existencia, mundos de significaciones, con figuras, pesos específicos y velocidades diferentes. La cartografía alimentaria en este documento que hoy entregamos, es una lista de chequeo sentido desde el estómago de quienes lo viven y que sirve para desplegar las dimensiones de los seres que lo sufren y que, mediante su uso, permitirá separar, clasificar, aislar y hasta abandonar, esos espacios reales, intelectualizados por las sociedades del conocimiento que gradan el hambre como: hambre moderada, hambre crónica, hambre crítica, hambre aguda, la estudian mediante datos de desnutrición y la valoran económicamente desde el consumo y producción, pero no la viven.

Por ello volvamos sobre el título. La palabra obsceno viene del latín "obscenus", la cual está formada por las raíces ob (hacia) y caenum (suciedad). Esta palabra se refiere a algo indecente, sin pudor, o que ofende a los sentidos. Otra versión dice que obscenus viene de ob (hacia) y scenus (escena) y que significa algo así como "fuera de escena", es decir que son cosas que no se muestran en una obra teatral, pero uno se las imagina. Obscenidad en latín obscenus, significando "repulsivo, detestable", (posiblemente derivado de ob caenum, literalmente "de la basura"). El término se usa principalmente en 
un contexto legal para describir expresiones (palabras, imágenes, acciones) que ofenden la moral sexual prevalente. A pesar de su largo uso formal e informal con una connotación sexual, la palabra aún mantiene el significado de "asqueroso" e incluso "desfavorable", como "beneficios obscenos" o "la obscenidad de la guerra". Puede usarse simplemente en el sentido de blasfemia o irreverencia, o puede señalar algo que es un tabú, indecente, aborrecible o repugnante. Vivimos una cultura obscena que funciona a partir de la carencia, represión y resignación para aprovecharse de los impulsos del hambre, y mantenemos el hambre como el gran negocio del mundo, como la estrategia militar o como la forma de obligar al trabajo; por ello concluyamos con otra frase de José Saramago premio Nobel de Literatura 1998: "La pornografía no es obscena, lo que es obsceno es que alguien se pueda morir de hambre".

\section{BIBLIOGRAFÍA}

- López E, A. (2006) ¿Qué es el hambre? Una aproximación conceptual y una propuesta experimental. México: Red Investigación en Salud. p 3. Disponible en http://site.ebrary.com/lib/biblioucaldassp/Doc?id=10119128\&ppg=3 consultado en Junio 2009.

- Messer E. (1995) Perspectivas antropológicas sobre la dieta. En: J. Alimentación y Cultura. España, Universidad de Barcelona. 27-81.

- Núñez S A (2005) Lo sublime y lo obsceno, geopolítica de la subjetividad. Editorial Libros del Zorzal, ISBN 9871081758, 9789871081752. 206 pp.

- Rodríguez Q L F. (2005) El mundo según Saramago. Saramago J, premio Nobel de Literatura 1998, el pasado 20 de junio en San Salvador, La Prensa Gráfica en Semanario de Prensa Libre • No. 52 • 03 de Julio de 2005 En http://www.prensalibre.com/pl/domingo/archivo/revistad/2005/julio05/030705/dcultura1. shtml consultado en junio 2009.

- Turró R. (1912) Orígenes del Conocimiento: El Hambre. Barcelona, Minerva. Wikimedia Foundation, Inc. (2008) Obscenidad En http://es.wikipedia.org/wiki/Obscenidad corregida 29 oct 2008. Consultada en junio de 2009.

1. Profesor titular Universidad de Caldas. Correo Electrónico: elmercr@ucaldas.edu.co 